\title{
British Women Writers and the French Revolution. Citizens of the World
}

\section{Christine Dousset}

\section{(2) OpenEdition \\ 1 Journals}

\section{Édition électronique}

URL : https://journals.openedition.org/ahrf/6593

DOI : 10.4000/ahrf.6593

ISSN : 1952-403X

Éditeur :

Armand Colin, Société des études robespierristes

\section{Édition imprimée}

Date de publication : 1 juin 2006

Pagination : 245-247

ISSN : 0003-4436

Référence électronique

Christine Dousset, «British Women Writers and the French Revolution. Citizens of the World », Annales

historiques de la Révolution française [En ligne], 344 | avril-juin 2006, mis en ligne le 02 juillet 2008, consulté le 23 avril 2022. URL : http://journals.openedition.org/ahrf/6593 ; DOI : https://doi.org/ 10.4000/ahrf.6593

Ce document a été généré automatiquement le 23 avril 2022.

Tous droits réservés 


\title{
British Women Writers and the French Revolution. Citizens of the World
}

\author{
Christine Dousset
}

\section{RÉFÉRENCE}

Adriana CRACIUN, British Women Writers and the French Revolution. Citizens of the World, Basingstoke, New York, Palgrave Macmillan, 2005, ISBN 1-4039-0235-6, 65 \$.

1 Le récent article de Matthew 0 . Grenby dans le n 342 d'octobre-décembre 2005 des Annales Historiques de la Révolution française soulignait la vitalité et l'abondance des travaux anglo-saxons concernant l'impact de la Révolution française sur la littérature anglaise, ce dont témoignait la riche bibliographie qui suivait son analyse historiographique. Le nouvel ouvrage d'Adriana Craciun, spécialiste de littérature britannique, en est un exemple. Il s'insère dans la lignée de ses recherches précédentes sur les femmes écrivains à l'époque de la Révolution, puisqu'elle a déjà publié plusieurs articles sur ce thème et coédité avec Kari Lokke, Rebellious Hearts : British Women Writers and the French Revolution en 2001. Le sous-titre devenu titre désormais doit être éclairci, car le propos d'Adriana Craciun est moins général qu'il pourrait le laisser penser. D'une part, elle restreint son analyse aux décennies 1790 et 1800, d'autre part, son travail n'englobe pas l'ensemble des femmes de Lettres de cette époque, mais s'attache à quelques auteurs privilégiés, dont elle analyse une partie de l'œuvre. Elle ne propose donc pas ici une vaste synthèse, mais plutôt un essai, poursuivant et complétant ses réflexions antérieures.

Comme l'indique son sous-titre, l'interrogation centrale de l'ouvrage porte sur le refus $\mathrm{du}$ nationalisme qu'affirment certaines femmes de Lettres britanniques, se voulant « citoyennes du monde ». Alors que la crise révolutionnaire et la guerre franco-anglaise exaspèrent de part et d'autre le sentiment national, conduisant les Anglais à rejeter la 
Révolution, un cosmopolitisme révolutionnaire teinté de francophilie apparait en Grande-Bretagne. Cette attitude très minoritaire, Adriana Craciun l'analyse à travers quatre femmes auteurs, qui sont au cœur de son étude: Mary Wollstonecraft, Mary Robinson, Helen Maria Williams et Charlotte Smith. Elle évoque aussi, parfois assez longuement comme dans le cas d'Anna Laetitia Barbauld, d'autres femmes écrivains telles Hannah More ou Fanny Burney par exemple, de sensibilité politique différente ou appartenant à la génération suivante. La mieux connue des lecteurs français est sans conteste Mary Wollstonecraft, pour son engagement féministe. Plusieurs de ses écrits ont d'ailleurs été réédités tout récemment, par Marie-Odile Bernez et Marcel Dorigny en 2003 au CTHS (Une Anglaise défend la Révolution française), Isabelle Bour aux Presses Universitaires de Saint-Étienne (Maria ou le Malheur d'être femme, traduction de The Wrongs of Woman), et Marie-Françoise Cachin chez Payot-Rivages (Défense des droits de la femme), les deux derniers en 2005. Les nombreux ouvrages de Charlotte Smith, Mary Robinson et Helen Maria Williams, poèmes, romans, lettres, qui furent abondamment traduits en français à leur parution ou peu après, n'ont par contre pas connu de réédition récente en français et n'ont pas non plus suscité de travaux facilement accessibles en France, semble-t-il, à l'exception de l'étude ancienne de Lionel Woodward sur Helen Maria Willams, reprise en 1977 chez Slatkine. C'est dire que l'ouvrage d'Adriana Craciun permet de découvrir des auteurs peu connus du public français en dehors des spécialistes de littérature anglaise.

Il est très représentatif des orientations actuelles des spécialistes de littérature britannique de l'époque révolutionnaire, telles qu'elles sont décrites par Matthew Grenby dans l'article précité. L'auteur propose une réinterprétation de l'engagement politique des femmes écrivains qu'elle étudie, réévaluant leur radicalisme et leur cosmopolitisme. Elle s'appuie pour cela à la fois sur une analyse littéraire de certaines œuvres, sans jugement de valeur sur leur qualité, et sur une approche plus historique du milieu dans lequel vivent leurs auteurs, pour reconstituer notamment leurs réseaux de relations, leurs déplacements. L'ouvrage est organisé en quatre copieux chapitres, précédés d'une longue introduction et suivis d'un épilogue. Il comporte également la liste des sources, poèmes, romans, pamphlets, correspondances et autres écrits, une bibliographie essentiellement anglo-saxonne, et quelques reproductions de gravures analysées dans le corps du livre. Chacun des chapitres, à travers un thème, insiste plus particulièrement sur l'une des auteures que privilégie Adriana Craciun, mais de manière le plus souvent non exclusive.

Le livre s'ouvre sur une introduction étoffée qui recontextualise l'essor du nationalisme en Grande-Bretagne à l'époque révolutionnaire et napoléonienne. Contre celui-ci, un cosmopolitisme nouveau naît en Angleterre du choc révolutionnaire, francophile, pacifiste, laïc et féministe, différent du cosmopolitisme aristocratique qui l'a précédé, et distinct du radicalisme nationaliste que défend Anna Laetitia Barbauld. Le premier chapitre intitulé "Female Philosophers». s'attache à percevoir le côté scandaleux de cette posture philosophique, à travers les écrits hostiles qu'elle suscite. L'expression, péjorative, est en effet utilisée par les adversaires de ces femmes philosophes, incarnées par Mary Wollstonecraft. Objets de violentes dénonciations de la part d'auteurs contre-révolutionnaires, y compris sur le registre sexuel, les «female philosophers » sont également critiquées par des auteures plus modérées du début du $\mathrm{XIX}^{\mathrm{e}}$ siècle, comme Elisabeth Hamilton et Amelia Opie, qui leur reprochent leur cosmopolitisme et leur refus de se placer sur le terrain religieux. Le deuxième chapitre est tout entier consacré à l'évolution politique de Mary Robinson, dont Adriana Craciun 
réévalue l'engagement auprès des radicaux anglais, à travers l'étude de certaines de ses œuvres peu connues, poèmes, romans et en proposant de lui attribuer différents écrits rédigés sous des pseudonymes. Personnalité originale, que l'on pourrait rapprocher d'Olympe de Gouges par certains côtés, elle commence sa carrière avant la Révolution comme actrice et maitresse du prince de Galles, puis devient femme de Lettres, s'engageant de manière de plus en plus nette dans le radicalisme. Par sa trajectoire originale, d'un modèle cosmopolite whig aristocratique à un républicanisme façonné par l'universalisme des Lumières, elle représente une forme spécifique de cosmopolitisme francophile et féministe. Le troisième chapitre qui porte sur la perception féminine de Robespierre s'attache plus particulièrement à l'œuvre de Helen Maria Williams. Radicale et francophile, cette proche des milieux girondins s'installe en France où elle tient salon, et connaît un court emprisonnement sous la Terreur. Les huit volumes de ses Letters from France, publiés entre 1790 et 1796, connaissent un très grand succès en Angleterre. Adriana Craciun s'appuie également sur les romans historiques de certaines romancières comme Helen Craik, Fanny Burney et Mary Robinson. Dans son roman, The Natural Daughter, cette dernière fait d'une de ses héroïnes, destinée à une fin tragique, la maîtresse de Robespierre... Dépeint de manière très négative dans ces écrits, Robespierre incarne selon l'auteur l'idéal rousseauiste et misogyne de la Vertu qui appelle la condamnation de ces auteurs féministes. On pourrait cependant objecter que rédigés après Thermidor, ces écrits portent surtout la marque de la réaction antijacobine de la période. Mais elle dénote aussi chez ces auteurs une certaine fascination pour le personnage et souligne leur silence sur les avancées que constitue pour les femmes la nouvelle législation française de la famille. Enfin, à partir de la situation des émigrés français, le dernier chapitre, «Citizens of the World", analyse de manière détaillée certains romans de Charlotte Smith. Poète et romancière de renom, mère de neuf enfants, elle appartient au même réseau de radicaux francophiles que Mary Wollstonecraft ou Helen Maria Williams. Les émigrés, particulièrement nombreux en Angleterre, inspirent toutes sortes d'écrits à des auteurs variés. Si leur sort est mis au service du nationalisme britannique par certains, comme Hannah More, il est au contraire pour d'autres l'occasion de défendre des positions cosmopolites. C'est le cas de Charlotte Smith, dont Adriana Craciun souligne l'évolution au fil de ses romans en faveur d'un cosmopolitisme de plus en plus affirmé, qui met en scène un Nouveau Monde utopique. L'épilogue montre comment ce courant politique et philosophique francophile se perpétue dans les écrits de certaines femmes comme Fanny Burney, Anne Plumptre et Lady Morgan à l'époque napoléonienne. Il débouche sur une remise en cause par l'auteur de la notion actuelle de "féminisme anglosaxon », accolée notamment à Mary Wollstonecraft, puisqu'il fut fortement influencé par l'expérience de la Révolution française.

5 À toutes les questions abordées au fil du livre, Adriana Craciun apporte des réponses nuancées, soulignant l'éventail des prises de position des unes et des autres. Fortement impliquée dans les débats historiographiques anglo-saxons qui la conduisent, un peu systématiquement parfois pour un lecteur français, à aborder les notions de classe, race et genre, elle tend à traiter la période de la Révolution française comme une "crise ", tendance générale comme le soulignait Matthew Grenby, à propos des travaux récents sur la littérature. Pour elle, les transformations provoquées par la Révolution française sont l'occasion pour les femmes écrivains qu'elle étudie d'imaginer et d'exprimer dans leurs écrits de nouvelles façons d'envisager ce qui semblait jusqu'alors intangible, comme l'ordre familial. L'ouvrage d'Adriana Craciun permet ainsi au lecteur peu 
familier de l'histoire littéraire anglaise de découvrir certaines personnalités de femmes remarquables et la richesse de la production littéraire féminine en Angleterre. À celui qui s'intéresse davantage à l'impact de la Révolution française elle-même, il ouvre d'intéressantes perspectives sur l'image de Robespierre, le rôle central de l'influence de Rousseau, la perception des émigrés français en Angleterre, l'existence de réseaux britanniques francophiles. Il suscite enfin des questions à propos de la réception en France des œuvres de ces auteurs britanniques influencés par la Révolution, dont les nombreuses traductions françaises constituent un exemple de la complexité des échanges culturels franco-britanniques. 